\title{
Gender Difference In Socio-Cultural Attitude Towards Appearance
}

\author{
Asma Latif \\ \& \\ Bushra Khan \\ Department of Psychology \\ University of Karachi
}

\begin{abstract}
The aim of this study was to find out the gender difference with reference to sociocultural attitude towards appearance among young adults. A cross sectional study was conducted on the sample consisted of 253 males and 256 female students of Karachi University with age range 18-24 years. Urdu translated version of Socio-Cultural Attitudes towards Appearance-4 (Thompson et al., 2015) scale was used to explore the gender difference in social and cultural aspect for ideal appearance. SATAQ-4 consist of five subscales two internal (thin/low body fat and muscular/ athlete) and three external (pressure peer, pressure family and pressure media). Males significantly scored higher on Internalization- Muscular/ Athletic and on all three subscales of external pressure (peer, family and media) as compared to female participants. The results of this study reveal that in our society, males are more conscious about their appearance and feel more pressure from external world through various means to retain their physique and fulfil social criteria of attractiveness. Although the female participants also facing internal pressures to have thin body having low fats to meet criteria of beauty as they scored higher on internalization - Thin / Low Body Fat subscale but the finding was insignificant.
\end{abstract}

Keywords: Gender, Appearance, Pakistan, Young Adults, SATAQ-4.

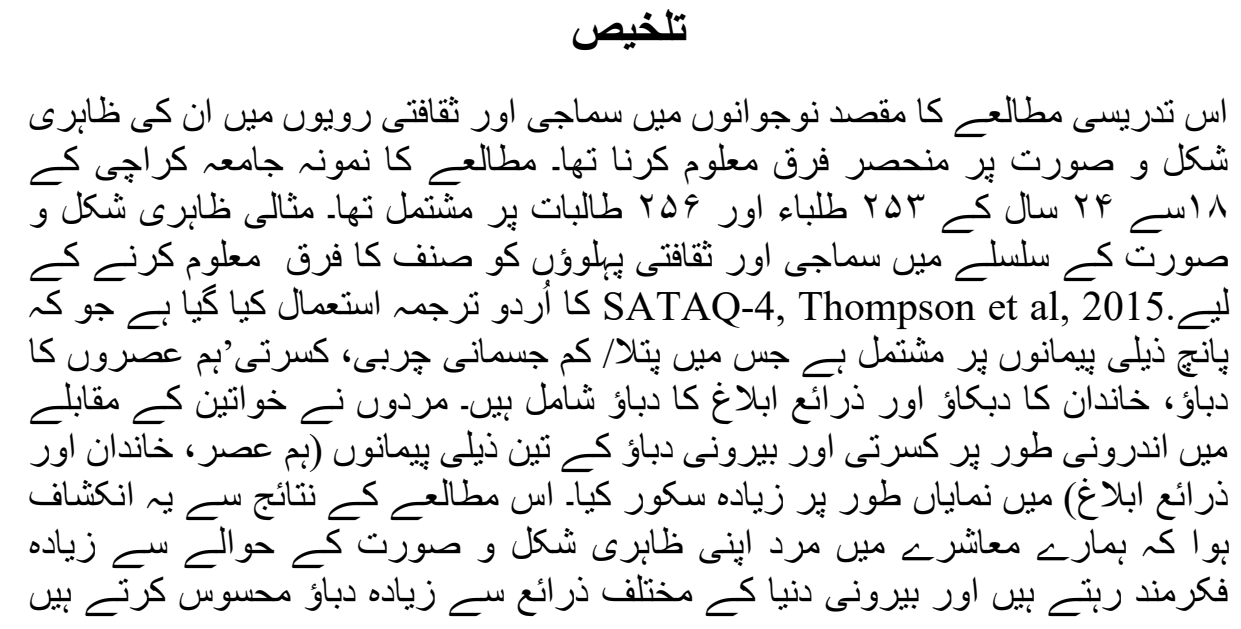




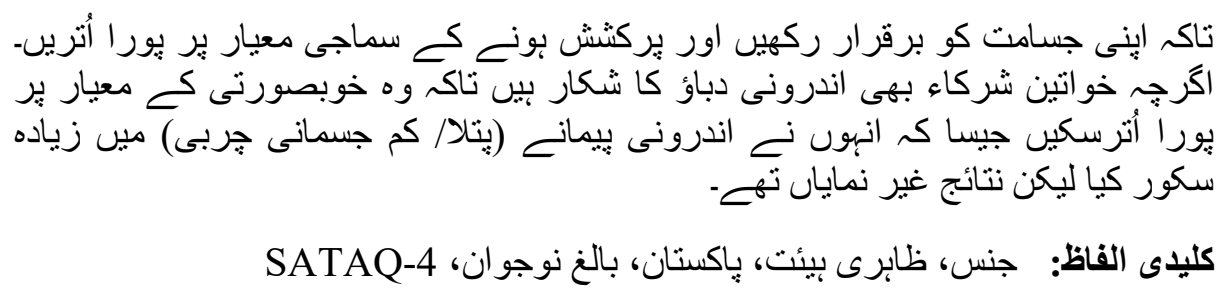

\section{Introduction}

According to Oxford Dictionary, appearance is "The way that someone or something looks" or "An impression given by someone". Appearance of an individual in most of the cases is the first thing in human personality that influences behavior of the perceiving person in face to face interaction (Efran, 1974; Zebrowitz, 1996). We have developed a social stereotype that a person who is beautiful would be more attractive (Snyder, Tanke \& Berscheid; 1977) Thus appearance based personality assessment is getting common in our society (Todorov, Mandisodza, Goren, \& Hall, 2005).

Concerns regarding physical appearance are increasing in society and reportedly females are more conscious about their appearance than males (Harris, \&Carr, 2000, Grift et al, 2016). There are numerous individual and social and culture related factors that contribute to these concerns. Appearance related schemas of individuals seem to be a significant part of body associated concern (Markus, 1977). Body image of an individual has multiple dimensions that include individual's own self-perception, attitudes and personal experiences regarding own body and physical appearance (Cash \& Pruzinsky, 1990, 2002). According to Cash $(1994,2002 a, 2002 b)$ various components contribute in development of body image which includes discrepancy between real and ideal self, level of satisfaction and dissatisfaction from own body.

Culture affects individual's personality and in return personality helps to develop culture of any society (Hossain, Ali, 2014). The term "society" means relationship between individuals which create and recreate an association thus directs and manages their conduct in numerous manners. When certain group of people shares their specific norms, values and believes they generate a culture. It affects the manner we think and behave in a particular situation. This is one of the reason theorists called culture as shaper of personality. It is a common assumption that people share certain general personality characteristics when born and bred in similar culture (Sincero, 2012).

Society has developed attitude of judging individuals on the basis of their physical appearance and beauty and consider it the only criteria to ascertain the potentials of Individuals. People give favor and appreciate those who look more attractive and smart. This assumption creates a halo effect in minds (Thorndike, 1920). Society considers thinness as criteria for beauty and attractiveness in women and muscular body as criteria 
for attractiveness in men who endeavor to attain these social desirable standards (Edwards, \& Launder, 2000, Crowne, \& Marlowe, 1960). Attainment of ideal appearance is becoming tougher for most of the people being unachievable and unrealistic, further obesity is also increasing among average person (Statistics Canada, 2002).

Appearance ideals in a society influence feelings and attitude of individuals by not only increasing body dissatisfaction but also developing eating pathologies (Feingold, \& Mazzella, 1998). Sociocultural factors that can affect our self-concept and body image perception are maturity, learning, media exposure, looks, civilization, relations, sex, and economic background (Haworth et al, 2010). Body image of an individual is not only visual self-image but it also consists of various factors like their thoughts, understandings, and insight related to their bodily outlook based on self-evaluation and societal responses (Cash \& Pruzinsky, 2002).

Family, peers and media are the major social and cultural agents who influence appearance related image of an individual and put pressure on them to achieve socially acceptable body. Media influences people by continuously showing models on screen, it builds up certain type of schemas regarding beauty in individual's mind and that become his or her criteria of beauty and attractiveness, later on these people develop body related dissatisfaction ( Hargreaves \& Tiggemann, 2002).

Continuous media messages are emphasizing an unrealistically lean model for females (Morrison et al., 2003) and encouraging muscular body for males with more focus on upper body muscles (Furnham et al, 2002). Media is promoting dissatisfaction regarding body image and people cannot ignore this fact (Hargreaves \& Tiggemann, 2002) as they have set size zero and tall slim looks as criteria of beauty which is not possible for everyone to attain (Grabe, Ward \& Hyde, 2008).

Individuals develop their image with the help of comments received from family and peers. These comments influence their body esteem, which further influences their selfevaluation regarding their own physical appearance (Mendelson, White, \& Mendelson, 2001). Social comparison theory states that this phenomenon is one of the way through which individuals can evaluate themselves (Morrison et al., 2004).

With respect to gender role our society displays a specific set of ideas and beliefs about how we expect men and women to dress up, behave and present themselves in the society (Carter \& Ortiz, 2008). There are certain cultural values and beliefs related to specific gender. Gender difference exists not only in relation to physical appearance but also in the role assigned to them (BSRI; Bem, 1974). These roles in society determine how individuals are expected to behave, speak, dress up, groom and conduct themselves basing on allocated gender (Bem, 1974). We expect from a women or girl to dress up in a 
typical feminine way and behave politely, be accommodative and nurturing whereas, from men and boys we expect them to be strong, aggressive and bold (Mehrabian \& Blum, 1997).

There are certain physical characteristics that are expected from a certain gender in every society. These characteristics and social roles vary from culture to culture, ethnic groups and social demands (Fallon, 1990). These attributes also change in the same society over time. Society expect woman to be slim and graceful whereas men to be tall and brawny (Field, Crothers, \& Kolbert, 2007). The criteria of beauty has been laid down by social standards of beauty instead of what people look in actual and how these people want to look.

Researches reveal that women always misjudge their actual weight and size, and male's ideal female body (Fallon \& Rozin, 1985). Perception of males regarding muscular body and women regarding excessive weight become the reason of their dissatisfaction and body image concerns. It is revealed in several studies that excessive body weight is not the area of concerns for males rather failing to have muscular body create body image dissatisfaction in them (Cafri \& Thompson, 2004; Olivardia et al, 2004; Pope, Olivardia et al, 1999).

Both males and females are equally affected by the attitude of society with regards to criteria of beauty and attractiveness defined for both genders (Seemanthini, T.S. (2015). Females are suffering more than males from this distorted self and body image as it negatively influence their personality and self-concept (Johnstone et al, 2008) and they develop certain pathologies later on (Mendelson et al, 2001). Social reinforcements specific to gender are the deciding factors which increase eating pathologies among male and female as compared to any biological factor (Andersen, \& DiDomenico, 1992).

\section{Review of Literature}

Women of nineteenth century are trying to be thinner and in order to achieve this they go through painful procedures and restrict their bodies to a certain level (Gray et al, 1992). Most of the females are striving hard to achieve lowest body weight to acquire socially acceptable concept of beauty (Cash \& Labarge, 1996). Anorexia nervosa, a fatal illness, may be developing due to these unhealthy and unattainable criteria of beauty. Women are not the only sufferers of these beauty standards of society, men are also striving to gain muscular body by adopting unhealthy means (e.g. steroids). Society as a whole is moving towards a stereotypical thought that Solomon, Zaichkowsky \& Polegato, 2005 mentioned "what is beautiful is good".

Throughout the history, physical appearance, specifically of women has been highly stressed upon and valued by the society. Media and other social factors continuously 
force women to meet an unrealistic physical ideal and in this struggle she develops disordered eating pattern and various body image disturbances (Twamley \& Davis, 1999). Most of the researches have shown that males are comparatively happier and satisfied with their body weight as compare to females (Leon et al, 1985) body shape (Fallon \& Rozin, 1985), and physical appearance (Pliner et al, 1990). Dissatisfaction related to looks is more common among females (Rozin \& Fallon, 1988). Due to these facts physical appearance, body image and eating disorders and their association with psychological health and performance was discussed as female specific concern (Rodin et al, 1985; Thompson et al, 1999).

Researchers have highlighted the fact that males were also experiencing weight and shape concerns (Mickalide, 1990). Manifestation of body dissatisfaction among males is different from that of female but it is comparable (Davis \& Cowles, 1991). Males are also affected with these social standards of beauty (Drewnowski \& Yee, 1987), so this body related dissatisfaction reach high degree in males (Mishkind, et al., 1986). Both males and females are dissatisfied with their physical appearance and body weight thus they try to achieve an unrealistic ideal body shape portrayed by media (Brennan, Lalonde, \& Bain, 2010). Researches reveal that individuals who want to gain more attention of other people tend to develop more eating pathologies just to achieve the social ideal of beauty and attractiveness. Social attitudes act as a mediator between eating pathology and attention seeking behavior (O'Neil \& Lafreniere, 2014).

According to recent studies body image dissatisfaction and appearance related concerns are effects of interpersonal (Vartanian, Giant, \& Passino, 2001) and socio cultural pressure on individuals (Fallon, 1990; Heinberg, 1996). Sociocultural attitude of people affect overall image of an individual and both internal and external factors of society are contributing in development of body related image (Seemanthini, 2015). Body image and appearance related concerns among females are increasing with the time and promoting eating disorder among them (Feingold \& Mazzella, 1998). There are chances that individuals may develop eating pathologies if body image is disturbed (Thompson et al, 1999) and when interpersonal pressure becomes difficult to manage (Tantleff-Dunn \& Gokee, 2002).

In the past few years researches on body image have increased dramatically and it mainly focuses on body image disturbance caused by various factors (Cash \& Pruzinsky, 1990., Thompson, 1990). Eating pathologies and body image related disturbances are also prevailing in eastern societies. Urbanization is one of the main factors behind this which has changed the criteria of beauty and made people more conscious about their physical appearance. Asian countries are also facing problem of eating disturbances and appearance related concerns (Pike \& Dunne, 2015). Previously it was a common concept that appearance related concerns were more common among females and males were 
comparatively lesser sufferers but recent studies revealed that in Asian countries the issue was increasing in both genders as a result of cultural transformation in eastern countries (Sharan \& Sundar, 2015).

In Pakistan we have somewhat conservative society and people have strong social bonding, their family structure, culture and norms are different from other Asian countries thus people have comparatively less exposure to western media. Due to a wave of modernization both male and females are now facing increase risk to develop eating disorder (Pike \& Dunne, 2015). In one of the studies conducted in 2008 on medical students the results reveals that majority of the students are somehow dissatisfied with their physique and appearance, according to the study women want thin body whereas males want muscular physique (Taqui, 2008). Being citizens of an under developed country we face many issues with regards to westernization and people easily get influenced by various fashion trends in vogue in western countries. Westernization is also affecting our cultural and social values thus people are becoming more conscious about their physical appearance which is developing eating related pathologies among them (Memon et al, 2012). These are few researches conducted so far about role of social influence in development of appearance related issues in Pakistan.

\section{Tripartite Model}

The current study is based on tripartite model of socio-cultural attitude. According to the model every individual is influenced or pressurized by various powerful social agents that include family, peers and media. These agents stick to certain ideal of appearance approved by culture and emphasize on thin body in case of female and muscular physique for males. These social agents put a continuous pressure on individuals to internalize certain appearance related ideal as criteria of attractiveness. These internalized ideal when become unachievable, create body dissatisfaction and leads towards pathological eating (Thompson, Schaefer \& Menzel, 2012).

\section{Rationale}

It is important to explore if males or females or both have desire and are into behaviours to achieve ideal appearance and the kind of pressure they feel from social and cultural factors to modify their appearance. The knowledge could therefore help researchers and policy makers to suggest ways to address these factors as well as suggest gender specific interventions. Despite the importance of the socio-cultural factors in relation to eating pathologies and body appearance issues, just one basic study was conducted in Pakistan titled "Relationship between social and cultural attitude towards appearance and body shape" (Kamrani, Khan \& Mustafa, 2015) and it didn't explore the gender difference on the basis of social and cultural attitudes towards appearance. Further, the study used 
English version of the instrument which has been developed in western world and based on western culture and values. The current study used Urdu translated and adapted version of the instrument which was more comprehensible for the population.

The aim of this study was to identify the gender difference in socio-cultural attitudes towards appearance with the following hypotheses;

1. There will be a gender difference in Internalization- Thin/Low body Fat.

2. There will be a gender difference in Internalization- Muscular/ Athletic.

3. There will be a gender difference in Pressure-Family.

4. There will be a gender difference in Pressure-Peer.

5. There will be a gender difference in Pressure-Media.

\section{Methods}

\section{Study Design and Participants}

A cross sectional study was conducted. Data was collected from University of Karachi, a public sector university that caters students from all socio-economic backgrounds. The data was collected from 509 students of various departments of University of Karachi. The sample consist total 509 university students, 253 males (49.70\%) and 256 female $(50.29 \%)$, studying in different department of Karachi University. Age range of the sample was 18 to 24 years $(\mathrm{M}=20.56, \mathrm{SD}=1.74)$. Data of the study was collected from those students who had no physical disability, any diagnosed illness or psychological disorder.

\section{Measures}

The Socio-Cultural Attitudes towards Appearance-4 (SATAQ-4; Thompson et al, 2015) scale was used in the study to find out the impact of social and cultural approach towards appearance. Urdu translated version of SATAQ-4 was used in the study which is a selfreported measure.

Socio-Cultural Attitude towards Appearance Questionnaire (SATAQ-4) was forward translated in to Urdu language by two bilingual translators. With the help of this approach two translated version of instrument was generated.

The instructions, items and all response formats of the two forward translated versions of the SATAQ-4 were presented to committee of experts that comprised of senior psychologists. They evaluated the instrument to see if it was equivalent to the original version primarily in term of its content and construct and gave their suggestions for improvement. The modified version was again presented to the 
committee and they approved translated version of the scale. This version was then pre-tested in focus group discussions having male and female young adults of age 18 years to 24 years. The goal of this discussion was to recognize their level of comprehension and relevance with all items. After amendments in translation identified in pre testing of scale, final forward translated version was generated. All the suggestions were then shared with the committee and were incorporated in the translated version after their approval. Urdu translated version of SATAQ-4 was translated back into the English language by independent bilingual translator. This back translated version was than approved by committee of experts. This method was suggested by Sousa and Rojjanasrirat (2011).

This 22-item questionnaire assesses social and cultural attitudes related to physical appearance and internal factors that forces us to focus on thin ideal and has certain link with the development of pathological eating pattern among male and female. The Socio-Cultural Attitudes towards Appearance Scale (SATAQ-4) comprises five subscales: Internalization - Thin/Low Body Fat, Internalization - Muscular/Athletic, Pressures - Family, Pressures - Peers, Pressures - Media. Scoring of this scale is carried out on 5 point Likert type format and response categories range from definitely disagree to definitely agree. Definitely disagree scored 1 and definitely agree scored 5 on this scale.

In SATAQ-4 there are two types of factors that formulate socio-cultural attitudes which affect appearance on an individual. One is internal factors that include internalizationthin/low body fat and internalization- muscular/athletic. These internal factors focus on the individual's desire and behaviour to achieve an ideal body. The other factor is external which include pressure- family, pressure-peers and pressure-media. These factors focus on pressure which an individual experience concerning his/her appearance from other individuals and media. Higher score in a particular domain reveal high intensity of that domain in individuals. Whereas overall high score reveal that the individuals face both social and cultural pressures internally as well as externally to maintain their physical appearance.

\section{Procedure}

Informed consent was taken from participants before collection of data and their participation was voluntary. The participants were briefed about the study and they were assured about confidentiality of their data. They were asked to be genuine in their responses on the scale. After taking the consent of the participants the questionnaires 
were given to them. Demographical information i.e. age, gender, siblings, birth order was also obtained from the participants.

\section{Results}

Using descriptive and inferential statistics, data was analysed. Mean, standard deviation, and Independent sample t-test were used. Also Cronbach Alpha value was calculated to find out the internal consistency reliability of SATAQ scale.

A reliability analysis using Cronbach Alpha was carried out on the Socio-Cultural Attitude towards Appearance Questionnaire (SATAQ) which comprises 5 subscales and 22 items in total. Table 1 shows the Cronbach Alpha values that ranged from high to moderate $(0.875$ to 0.523$)$ for all scales of Urdu version of SATAQ scale, indicating that all items measure their respective constructs.

Table: 1

Reliability analysis of SATAQ scale via cronbach alpha

\begin{tabular}{|l|c|c|}
\hline Variable & Number of items & Cronbach's Alpha \\
\hline Internalization- Thin/Low body Fat & 5 & 0.778 \\
\hline Internalization- Muscular/ Athletic & 5 & 0.709 \\
\hline Pressure- Family & 4 & 0.523 \\
\hline Pressure- Peer & 4 & 0.779 \\
\hline Pressure- Media & 4 & 0.875 \\
\hline
\end{tabular}

Table 2 shows result of independent t-test which the male participants scored significantly higher than female participants on internal aspect of pressure such as Internalization- Muscular/ Athletic $(\mathrm{M}=14.92, \mathrm{SD}=4.50, \mathrm{M}=11.55, \mathrm{SD}=4.23$ respectively) and indicate that males are more inclined to have muscular and athletic body as compared to females. They also had significantly higher score on external pressures such as Pressure- Family $(\mathrm{M}=9.73, \mathrm{SD}=3.55, \mathrm{M}=8.76, \mathrm{SD}=3.70$ respectively), Pressure- Peers $(\mathrm{M}=9.21, \mathrm{SD}=4.01, \mathrm{M}=7.24, \mathrm{SD}=3.76$ respectively), Pressure- Media ( $\mathrm{M}=8.85, \mathrm{SD}=5.78, \mathrm{M}=7.68, \mathrm{SD}=4.53$ respectively $)$ as compared to females and indicate that they feel more pressure from family and peers to control and reduce weight and gain ideal body shape and size. Whereas female participants scored slightly higher only on internalization- Thin/Low Body Fat $(\mathrm{M}=14.05, \mathrm{SD}=5.72, \mathrm{M}=$ $13.47, \mathrm{SD}=4.60$ respectively) but the finding was insignificant. 
Table: 2

Gender Differences in Personal, Social and Cultural Attitude towards Appearance subscales( $(N=509)$

\begin{tabular}{|c|c|c|c|c|c|c|c|c|c|}
\hline & \multicolumn{2}{|c|}{$\begin{array}{c}\text { Males } \\
(\mathrm{n}=253)\end{array}$} & \multicolumn{2}{|c|}{$\begin{array}{c}\text { Females } \\
(\mathrm{n}=256)\end{array}$} & & & \multicolumn{2}{|c|}{$95 \% \mathrm{Cl}$} & \multirow{2}{*}{$\begin{array}{c}\text { Cohen's } \\
\mathrm{D}\end{array}$} \\
\hline Variables & $\mathrm{M}$ & $\mathrm{SD}$ & $\mathrm{M}$ & $\mathrm{SD}$ & $\mathrm{T}(509)$ & $\mathrm{p}$ & $\mathrm{LL}$ & $\mathrm{UL}$ & \\
\hline $\begin{array}{c}\text { Internalization- } \\
\text { Thin/Low } \\
\text { body Fat }\end{array}$ & 13.47 & 4.60 & 14.05 & 5.72 & 1.26 & 0.20 & -1.48 & 0.32 & 0.11 \\
\hline $\begin{array}{c}\text { Internalization- } \\
\text { Muscular/ } \\
\text { Athletic }\end{array}$ & 14.92 & 4.50 & 11.55 & 4.20 & 8.73 & 0.00 & 2.61 & 4.12 & 0.77 \\
\hline $\begin{array}{c}\text { Pressure- } \\
\text { Family }\end{array}$ & 9.73 & 3.55 & 8.76 & 3.70 & 3.01 & 0.00 & 0.33 & 1.60 & 0.27 \\
\hline \begin{tabular}{c} 
Pressure- Peer \\
\hline $\begin{array}{c}\text { Pressure- } \\
\text { Media }\end{array}$
\end{tabular} & 9.21 & 4.01 & 7.24 & 3.76 & 5.71 & 0.00 & 1.29 & 2.64 & 0.50 \\
\hline
\end{tabular}

Note: $\mathrm{SD}=$ Standard Deviation, $\mathrm{n}=$ Number of Participants, $\mathrm{LL}=$ Lower Limit, $\mathrm{UL}=$ Upper Limit, CI= Confidence Interval.

\section{Discussion}

Objective of the current research study was to find out the gender difference with respect to socio-cultural attitudes towards appearance among university students. Previous researches reveal that body related dissatisfaction is common among females only and they strive hard to achieve their perceived ideal body (Pasha, \& Golshekoh, 2009). Whereas, findings of this study reveals that males have more desire to achieve ideal body appearance than females. They feel more pressure from family, peers and media to improve their physical outlook. 
Socio-Cultural theory highlights the importance of both social and cultural pressures on males and females to modify their body physique and attain socially desirable body shapes (Cusumano \& Thompson, 1997). In male dominating society females are more vulnerable to be criticized by males on appearance related things which may develop pathologies in them (Fallon, Katzman \& Wooley, 1994). According to social ideal a beautiful woman is the one with thin body whereas ideal male body is muscular, tall and has good build (Waaler-Loland, 1998). Both males and females may develop a sense of pride and confidence after achieving socially acceptable body shape (Davis, Dionne, \& Lazarus, 1996) similarly, those who fails to get the ideal body size feel under confident (Freedman, 1984). Social standards of beauty develop drive for thinness among female and desire to be muscular among males (McCreary \& Sasse, 2000). There exists a vast difference between real and ideal body weight of females as compared to males (McKinley, 1998). With the passage of time ideal male figure is getting muscular (Pope et al, 1999). In both genders desirable body should have less body fat . The results of the current study proves that there is no difference in both males and females in having internal desire to have thin or low body fat. Result on subscale internalization thin/low body fat is not significant as expected because both genders have equal desire to have low body fat. Females wants to have smaller body than their existing size whereas, males are confused between having a larger or smaller body (Stanford \& Mccabe, 2002). Males want to have body with more muscles and less body fats to look more attractive. The results of this study also support the fact that males have internalized pressure to attain such body and to look more athletic whereas females want to have thinner body but do not want to look muscular like athletes.

In our society we have specific gender related roles and have different body perception of each gender. We expect males to perform those roles that require physical strength and agility whereas we demand softest and nurturance related role from female which does not require any physical strength as such. Because of socially assigned roles, ideal perception and criteria of attractiveness for males' body is strong muscles whereas for females thin and lean body structure is supposed to be attractive and beautiful. Both male and female strive hard to achieve ideal body structure laid down by society and promoted/instigated through various means like media, peers and family members etc. The aspiration of having muscular body by males to perform hard tasks has been validated by results of this study as male participants scored significantly higher than female participants on internalization muscular/athlete subscales which means that male are more attracted towards development of muscular and athletic type body as compared to females. Attitudes with regards to role of males in society demand males to be strong and powerful, for this, they need to develop muscular body and strong physique which ultimately become the criteria of beauty and attractiveness for them. Various researches reveals that female are now more attracted to males with strong and muscular body which is raising body dissatisfaction among males and they are striving hard to achieve socially 
desirable physique (Raevuori et al., 2006). Both males and females want to bring changes in weight females want to lose weight by any means whereas males are also using both healthy and unhealthy means to achieve their desired body and physique (Cruze, 2014).

Although results of our study reveal that male participants scored significantly higher in most of the subscales of the socio-cultural attitude towards appearance questionnaire (SATAQ). Comparative mean scores of both genders on various subscales of SATAQ reveals that mean of female participants is slightly higher on internalization thin/low body fat subscale. Female are more aspired to look thin and have low body fat as compared to males because this is socially acceptable look for female. In our society majority of the women are striving hard to attain a lean and thin body shape with almost zero body fats and this has become the standard of beauty and criteria of attractiveness thus the result support this mind-set of society (Zhang, Qian \& Fu, 2018). The main point of concern in Internalization: Thin/Low Body Fat subscale is that it display stronger association with development of eating pathologies and body related concerns than the Internalization: Muscular/Athletic subscale. Those males who want to attain thin body have more chances to develop eating pathologies than the males who want to obtain muscular body (Thompson et al, 2015).

Both cultural and social factors play a significant role in body image development and formulate attitude of society towards appearance. Tripartite Influence Model consists of social and cultural factors which include family, media and peers (Keery et al, 2004). In Asian culture, family is the strongest tie that joint people together and make a happy and healthy bond among them. Family has a massive role in development of self-perception and it affects both in positive and negative ways. Parents give confidence to their children to think good about their looks and appearance. They also give them assurance and belief to face society even with average looks and not like beauty standards of society. Parents have an important role in transferring social and cultural messages concerning socially acceptable or ideal body to their children (Stice, 1994). Researches demonstrate that mother has more influence on body related attitude of sons whereas, fathers has more influence on daughters (Vincent \& McCabe, 1999). Among adolescents influence of mothers seems to be more on body image similarly fathers seems to have more influence on exercise and dieting (Ricciardelli, McCabe \& Banfield, 1999). Results of the study demonstrate that male participant scored high on Pressure- Family subscale as compared to female which indicate that males have more effect of remarks and attitude of family and parents on them as compared to females. The effect is increasing pressure on them to look more attractive and attain ideal body.

Media appears to be among the key factors in development of people's perspective about their own selves as they try to strive to achieve that unrealistic ideal look and body shapes that media promote every day through various means (Stice et al., 1994). In these days people do not want to be healthy and fit, they just want to look like the model which 
media is espousing as a role model (Clay, Vignoles \& Dittmar, 2005). Results analysis of this study reveals the fact that males are more affected with the image of beauty and attractiveness portrayed by the media and they feel significant pressure as compared to females from media to improve their looks and attain socially desirable physique. Males are now more dissatisfied with their physical appearance and physique as compared to females and media is one of the reasons behind it. They have started comparing themselves with the ideal images presented by media and they feel themselves as failures when unable to meet cultural standards of attractiveness. In these days media image of men has become more lean and muscular than never before (Pope et al, 1999) and increased beauty standards for males (Leit, Pope \&Gray, 2000). According to various researches viewing such images on media may further lead towards body dissatisfaction among males (Agliata \& Tantleff-Dunn, 2004) and as a result their body esteem effected (Humphreys \& Paxton, 2004). Media exposure even for a shorter period of time change view of males about their body shape (Leit, Gray, Pope, 2002). Muscular male models exposure on media is directly related with development of decrease in body satisfaction (Lorenzen, Grieve \& Thomas, 2004).

Peers are another factor in development of self-image. As one grows up with his/her social group, it criticizes them on physical appearance and looks. For example, kids tend to be shorter, fatter, and skinnier than others are pressurised from peers to look smarter and attractive which makes them more conscious about their physique and appearance and as a result they strive for that beauty criteria. Instead of quality of relationship among peers the direct peer influence is more significant (Vincent \& McCabe, 2000), the nature of the interaction with peers is also major factor (Jones et al., 2004). Results of the study reveal that male participant secured higher score than females on pressure- peer subscale. Peers can exert diverse influences on body image of both males and females which may further lead towards development of body dissatisfaction among them. Social comparison and internalization can be mediators of certain influential factors. There is need to identify these mediators to prevent body dissatisfactions (Keery et al., 2004). Both girls and boys put their maximum efforts to attain criteria of beauty and attractiveness set by their circle of friends or colleague. Among teen agers these peer influence or pressure act as fuel on fire. Boys have the same attitude regarding their body image as females have. In teen ages they try hard to achieve more muscular body and to have macho looks to give image of a man (Helfert \& Warschburger, 2013).

Society pressurize individual in various ways to behave and think in a socially acceptable way and follow the set criteria. This social pressure in different forms on both males and females decrease body satisfaction level and increase desire to have an unrealistic body shape that meet ideal social standards which is getting thinner day by day for females and muscular for males (Fallen \& Rozin, 1985). Gender difference in pressure from peers and family is due to fact that now a day's males perceive more social stress from peers and 
family to achieve an ideal body having less fat and more muscles. Males are more exposed in society and have more social interaction than females thus to attain socially acceptable body shape is becoming more important for them (Pope et al., 2000).

In western society women are not the only victim of body dissatisfaction now as males show equal level of dissatisfaction from their looks, physique and body weight (Aubrey, 2006). Results of this study also support this fact that males are not satisfied with their physique and have more socio-cultural pressure from various means to achieve ideal body shape and size. Various social and cultural factors are participating in this body image dissatisfaction and media is playing an important role in both western and eastern countries (Becker, 2004). Exposure of media creates more internal pressure among individuals to attain socially acceptable body shape and size (Brittney \& Schrick, 2005). Media is effecting thin ideal internalization either directly or indirectly by promoting unrealistic body image (Anschutz et al, 2009) and people who are more aware of this societal pressure to look attractive have more chances to indulge in body related concerns (Cusumano \& Thompson, 1997).

It should not be the decision of social standards of beauty that how women and men should look and view themselves because every individual has its own uniqueness that makes them beautiful and attractive. Having inner beauty and treating people with love and kindness is far better than outer beauty (Cusumano \& Thompson, 1997). Current society pressurize individuals to fit into it and due to this external influence they try to look as socially acceptable as possible and in this struggle they forget about their own beauty and uniqueness which make them different in society.

\section{Conclusions}

Social, personal and cultural factors have great importance in development of individual's self-image; body image and insight about own self. As humans are social animal therefore they have to follow rules and regulations set by society but at times these social attitudes affect them badly. Instead of inner beauty, criterion of beauty and attractiveness set by society is physical appearances. People strive hard to achieve the unrealistic criteria laid down by society. Muscular body has become criteria of beauty for males and lean and thin figure for females. Unfortunately it is same for everyone regardless of their body type and built. This unrealistic beauty criterion can develop dissatisfaction among individuals and lead towards unhealthy life style and eating pathologies. There is a dire need for people to identify own body type and adopt a healthy eating style and live a happy and healthy life, instead of just focusing on impracticable body ideals of society. Also it is important to design gender sensitive interventions to create awareness with reference to various social and cultural factors related to appearance. 


\section{References}

Agliata, D. \& Tantleff-Dunn, S. (2004). The Impact of Media Exposure on Males' Body Image. Journal of Social and Clinical Psychology, vol.23, pp.7-22.

Algars, M., Santtila, P. \& Sandnabba, N. K. (2010). Conflicted Gender Identity, Body Dissatisfaction and Disordered Eating in Adult Men and Women. Sex Roles, vol.63, pp.118-125.

Andersen, A. E. \& Di Domenico, L. (1992). Diet vs. Shape Content of Popular Male and Female Magazines: A Dose-Response Relationship to the Incidence of Eating Disorders? International Journal of Eating Disorders, vol.11:3, pp.283-287.

Anschutz, D., Engels, R., Leeuwe, J.V. \&Strien, T.V. (2009). Watching Your Weight? The Relations between Watching Soaps and Music Television and Body Dissatisfaction and Restrained Eating in Young Girls.Psychology \& Health, vol.24:9, pp.1035-1050.

Arrusi, B. \&Baneshi, M. (2017).Body Dissatisfaction among Iranian Youth and Adults.Cadernos de SaúdePública, vol.33:9. doi: 10.1590/0102-311x00024516

Aubrey, J. S. (2006). Effects of Sexually Objectifying Media on Self-Objectification and Body Surveillance in Undergraduates: Results of a 2-Year Panel Study. Journal of Communication, vol.56:2, pp.366-386.

Bandini, E., Fisher, A. D., Castellini, G., Lo Sauro, C., Lelli L., Meriggioloa, M. C. \&Ricca, V. (2013). Gender Identity Disorder and Eating Disorders: Similarities and Differences in Terms of Body Uneasiness. Journal of Sexual Medicine, vol.10, pp.1012-1023.

Becker, A. E. (2004). Television Disordered Eating and Young Women in Fiji: Negotiating Body Image and Identity during Rapid Social Change. Culture, Medicine and Psychiatry, vol.28, pp.533-559.

Bem, S. L. (1974). The measurement of Psychological androgyny. Journal of Consulting and Clinical Psychology, vol.42:2, pp.155-162. 
Bodlund, O. \&Armelius, K. (1994). Self-Image and Personality Traits in Gender Identity Disorders: An Empirical Study. Journal of Sex and Marital Therapy, vol.20, pp.303-317.

Brennan, M.A., Lalonde, C.E. \& Bain, J.L (2010). Body Image Perceptions: Do Gender Differences Exist? Psi Chi Journal of Undergraduate Research, vol.15:3, pp.130-138.

Brownell, K. D. (1991). Dieting and the Search for the Perfect Body: Where Physiology and Culture Collide. Behaviour Therapy, vol.22, pp.1-12.

Brittney, E. H. \& Schrick, B.S. (2005). Television's Relationship to Body Dissatisfaction in College Women. http://citeseerx.ist.psu.edu/viewdoc/download?doi=10.1.1. $855.3217 \&$ rep $=$ rep $1 \&$ type $=$ pdf

Bulian, P.A. \& Randic, A.N. (2007). Sociocultural Attitudes Towards Appearance and Body Dissatisfaction among Adolescent Girls in Croatia. Eating and Weight Disorder, vol.12:4, pp.86-91.

Cafri, G. \& Thompson, J. K. (2004).Measuring Male Body Image: A Review of the Current Methodology. Psychology of Men and Masculinity, vol.5, pp.18-29.

Carter, S.K. \& Ortiz, M.M. (2008). Ideal Female and Male Bodies: An Analysis of College Students' Drawings. The Journal of Public and Professional Sociology, vol.2:1, pp.1-23.

Cash, T.F. \& Pruzinsky, T. (1990). Body Image: Development, Deviances and Change. New York: Guilford Press.

Cash, T.F. (1994). Body-Image Attitudes: Evaluation, Investment and Affect. Perceptual and Motor Skills, vol.78, pp.1168-1170.

Cash, T.F. (2000a). Body-Image Assessments: Manuals and Questionnaires. www.bodyimages.com

Cash, T.F. (2000b). Manual for the Appearance Schemas Inventory. Unpublished Manuscript, Old Dominion University, Norfolk, VA.

Cash, T.F. \& Pruzinsky, T. (2002). Body Image: A Hand Book of Theory, Research and Clinical Practice. New York: Guilford Press. 
Cash, T.F. Ancis, J.R. \& Strachan, M.D. (1997).Gender Attitudes, Feminist Identity, and Body Images among College Women. Sex Roles, vol.36:7, pp.433-447.

Cash, T. F. \& Labarge, A. S. (1996). Development of the Appearance Schemas Inventory: A New Cognitive Body-Image Assessment. Cognitive Therapy and Research, vol.20:1, pp.37-50.

Clay, D., Vignoles, V.L. \& Dittmar, H. (2005). Body Image and Self-Esteem among Adolescent Girls: Testing the Influence of Socio-Cultural Factors. Journal of Research on Adolescence, vol.15:4, pp.451-477.

Cohn, L. D. \& Adler, N. E. (1992). Female and Male Perceptions of Ideal Body Shapes: Distorted Views among Caucasian College Students. Psychology of Women Quarterly, vol.16, pp.69-79.

Crowne, D. P. \& Marlowe, D. (1960). A New Scale of Social Desirability Independent of Psychopathology. Journal of Consulting Psychology, vol.24:4, pp.349-354.

Cruz, J. S. (2014, March 10). Body-Image Pressure Increasingly Affects Boys. Retrieved from https://www.theatlantic.com/health/archive/2014/03/body-image-pressureincreasingly-affects-boys/283897/

Cusumano, D. L. \& Thompson, J. K. (1997). Body Image and Body Shape Ideals in Magazines: Exposure, Awareness and Internalization. Sex Roles: A Journal of Research, vol.37:9-10, pp.701-721.

Davis, C. \& Cowles, M. (1991). Body Image and Exercise: A Study of Relationships and Comparisons between Physically Active Man and Women. Sex Roles, vol.25, pp.33-44.

Davis, C., Dionne, M. \& Lazarus, L. (1996). Gender-Role Orientation and Body Image in Women and Men: The Moderating Role of Neuroticism. Sex Roles, vol.35, pp.493-505.

Drewnowski, A. \& Yee, D. K. (1987). Man and Body Image: Are Males Satisfied with their Body Weight? Psychosomatic Medicine, vol.49, pp.626-634.

Edwards, S. \& Launder, C. (2000). Investigating Muscularity Concerns in Male Body Image: Development of the Swansea Muscularity Attitudes Questionnaire. International Journal of Eating Disorders, vol.28, pp.120-124. 
Efran, M. G. (1974). The Effect of Physical Appearance on the Judgment of Guilt, Interpersonal Attraction and Severity of Recommended Punishment in a Simulated Jury Task. Journal of Research in Personality, vol.8, pp. 45-54.

Fallon, A. E. \& Rozin, P. (1985).Sex Differences in Perceptions of Desirable Body Shape. Journal of Abnormal Psychology, vol.94, pp.1045-1056.

Fallon, A. (1990). Culture in the Mirror: Sociocultural Determinants of Body Image. In T. F. Cash \& T. Pruzinsky (Eds.), Body Images: Development, Deviance and Change (pp. 80-109). New York, NY, US: Guilford Press.

Fallon, P., Katzman, M.A. \&Wooley, S.C. (1994). Feminist Perspectives on Eating Disorders. New York: Guilford Press.

Field, U.E., Crothers, L.M. \& Kolbert, J.B. (2007) Adolescent Female Gender Identity and Attraction to Male Bullies and Victims. Journal of Emotional Abuse, vol.7:1, pp.1-15.

Feingold, A. \& Mazzella, R. (1998). Gender Differences in Body Image Are Increasing. Psychological Science, vol.9:3, pp.190-195.

Freedman, R.T. (1984). Reflections on Beauty as it Relates to Health in Adolescent Females. Women and Health, vol.9, pp.29-45.

Furnham, A., Badmin, N. \& Sneade, I. (2002). Body Image Dissatisfaction: Gender Differences in Eating Attitudes, Self Esteem and Reason for Exercise. The Journal of Psychology, vol.136, pp.581-596.

Grabe, S., Ward, L. M. \& Hyde, J. S. (2008). The Role of the Media in Body Image Concerns among Women: A Meta-Analysis of Experimental and Correlational Studies. Psychological Bulletin, vol.134:3, pp.460-476.

Gray, J.J., Mosimann, J.E. \& Ahrens, A.H. (1992). Cultural Expectations of Thinness in Women: An Update. International Journal of Eating Disorder, vol.11:1, pp.85-89.

Grift, T.C., Kettenis, P.T., Steensma, T.D., Cuypere, G., Appelt, H.R., Haraldsen, I.H., Dikmans, R.G., Cerwenka, S.C. \& Kreukels, B.P. (2016).Body Satisfaction and Physical Appearance in Gender Dysphoria. Archive Sex Behavior, vol.45, pp.575-585. 
Harris, D. L. \&Carr, A.T. (2000). Prevalence of Concern about Physical Appearance in the General Population. British Journal of Plastic Surgery, vol.54, pp.223-226.

Hargreaves, D. \& Tiggemann, M. (2002). The Effect of Television Viewing on Mood and Body Dissatisfaction: The Role of Appearance-Schema Activation. Journal of Social and Clinical Psychology, vol.21:3, pp.287-308.

Helfert, S. \& Warschburger, P. (2013). The Face of Appearance-Related Social Pressure: Gender, Age and Body Mass Variations in Peer and Parental Pressure during Adolescence. Child and Adolescent Psychiatry and Mental Health, pp.7-16. http://www.capmh.com/content/7/1/16.

Hossain, F.M. \& Ali, M.K. (2014).Relation between Individual and Society. Open Journal of Social Sciences, vol.2, pp.130-13.

Humphreys, P. \& Paxton, S. (2004). Impact of Exposure to Idealized Male Images on Adolescent Boy's Body Image. Body Image, vol.1, pp.253-266.

Jones, D. C., Vigfusdottir, T. H. \& Lee, Y. (2004). Body Image and the Appearance Culture among Adolescent Girls and Boys: An Examination of Friend Conversations, Peer Criticism, Appearance Magazines and the Internalization of Appearance Ideals. Journal of Adolescent Research, vol.19, pp.323-339.

Johnstone, A. M., Stewart, A. D., Benson, P. J., Kalafati, M., Rectenwald, L. \& Horgan, G. (2008).Assessment of Body Image in Obesity Using a Digital Morphing Technique. Journal of Human Nutrition and Dietetics, vol.21, pp.256-267.

Kamrani, F., Khan, B. \&Mustafa, K. (2015).The Relationships between Socio-Cultural Attitudes towards Appearance Inherent in Media and Preoccupation with Body Shape among University Students. Bahria Journal of Professional Psychology, vol.14:2, pp.20-31.

Keery, H., Van den Berg, P. \& Thompson, J. K. (2004). An Evaluation of the Tripartite Influence Model of Body Dissatisfaction and Eating Disturbance with Adolescent Girls. Body Image, vol.1, pp.237-251.

Leit, R. A., Gray, J. J. \& Pope, H. G. (2002). The Media's Representation of the Ideal Male Body: A Cause for Muscle Dysmorphia. International Journal Eating Disorders, vol.31, pp.334-338. 
Leit, R. A., Pope, H. G. \& Gray, J. J. (2000). Cultural Expectations of Muscularity in Men: The Evolution of Playgirl Centrefolds. International Journal of Eating Disorders, vol.29, pp.90-93.

Leon, G. R., Carroll, K., Chernyk, B. \& Finn, B. (1985). Binge Eating and Associated Habit Patterns within College Students and Identified Bulimic Populations. International Journal of Eating Disorders, vol.4, pp.43-57.

Lorenzen, L., Grieve, F. G. \& Thomas, A. (2004). Exposure to Muscular Male Models Decreases Men's Body Satisfaction. Sex Roles, vol.51, pp.743-748.

Markus, H. (1977). Self-Schemata and Processing Information about the Self. Journal of Personality and Social Psychology, vol.35, pp.63-78.

McCreary, D.R. \& Sasse, D.K. (2000).An Exploration of the Drive for Muscularity in Adolescent Boys and Girls. Journal of American College Health, vol.48, pp.297-304.

McKinley, N.M. (1998). Gender Differences in Undergraduates' Body Esteem: The Mediating Effect of Objectified Body Consciousness and Actual/Ideal Weight Discrepancy. Sex Roles, vol.39, pp.113-123.

Mehrabian, A. \& Blum, J. (1997).Physical Appearance, Attractiveness and the Mediating Role of Emotions. Current Psychology, vol.16:1, pp.20-42.

Mendelson, B. K., White, D. R. \& Mendelson, M. J. (2001). Body Esteem Scale for Adolescents and Adults. Journal of Personality Assessment, vol.76, pp.90-106.

Memon, A.A., Adil1, S.E., Siddiqui, E.U., Naeem, S.S., Ali, S.A. \& Mehmood, K. (2012).Eating Disorders in Medical Students of Karachi, Pakistan. A CrossSectional Study. Bio Med Central Research Notes. http://www.biomedcentral.com/1756-0500/5/84

Mickalide, A.D. (1990). Sociocultural Factors Influencing Weight among Males. In A.E. Andersen (Ed.), Males with Eating Disorders, pp. 30-39. New York: Brunner/Mazel.

Mishkind, M. E., Rodin, J., Silberstein, L. R. \& Striegel-Moore, R. H. (1986). The Embodiment of Masculinity. American Behavioral Scientist, vol.29:5, pp.545-562. 
Morrison, T. G., Kalin, R. \& Morrison, M. A. (2004). Body Image Evaluation and Investment among Adolescents: A Test of Sociocultural and Social Comparison Theories. Adolescence, vol.39, pp.571-592.

Morrison, T. G., Morrison, M. A. \& Hopkins, C. (2003).Striving for Bodily Perfection: An Explanation for the Drive for Masculinity in Canadian Males. Psychology of Men and Masculinity, vol.4, pp.111-120.

O'Neil, A.I. \& Lafreniere, K. (2014).Metamotivational Tendencies, Sociocultural Attitudes and Risky Eating Behaviors. Journal of Motivation, Emotion, and Personality, vol.2:1, pp.50-57.

Olivardia, R., Pope, G. P., Borowiecki, J. J. \& Cohane, G. H. (2004). Biceps and Body Image: The Relationship between Muscularity and Self-Esteem, Depression and Eating Disorder Symptoms. Psychology of Men and Masculinity, vol.5, pp.112-120.

Pasha, G. \& Golshekoh, F. (2009).Relationship between Socio Cultural Attitudes, Appearance and Body Dissatisfaction among Students of Islamic Azad University. Journal of applied sciences, vol.9:9, pp.1726-1732.

Pike, K.M. \& Dunne, P.E. (2015). The Rise of Eating Disorders in Asia: A Review. Journal of Eating Disorders, vol.3:33. doi 10.1186/s40337-015-0070-2

Pope, H. G., Olivardia, R., Gruber, A. J. \&Borowiecki, J. (1999).Evolving Ideals of Male Body Image as Seen through Action Toys. International Journal of Eating Disorders, vol.26, pp.65-72.

Pope, H.G., Gruber, A.J., Mangweth, B., Bureau, B., ChristinedeCol., Jouvent, R. \& Hudson, J.I. (2000). Body Image Perception among Men in Three Countries. American Journal of Psychiatry, vol.157, pp.1297-1301.

Pliner, P., Chaiken, S. \& Flett, G.(1990). Gender Differences in Concern with Body Weight and Physical Appearance Over the Life Span. Personality and Social Psychology Bulletin, vol.16, pp.263-273.

Raevuori, A., Keski-Rahkonen, A., Bulik, C.M., Rose, R.J., Rissanen, A. \&Kaprio, J. (2006). Muscle Dissatisfaction in Young Adult Men. Clinical Practice and Epidemiology in Mental Health, vol.2:6, pp.1-8.

Ricciardelli, L., McCabe, M.P. \& Banfield, S. (1999). Sociocultural Influences on Body Image and Body Changes Methods in Adolescent Males. Journal of Adolescent Health, vol.26, pp.3-4. 
Rodin, J., Silberstein, L. R. \& Streigel-Moore, R. H. (1985). Women and Weight: A Normative Discontent. In T. B. Sonderegger (Ed.), Nebraska Symposium on Motivation: Vol. 32. Psychology and Gender (pp. 267-307). Lincoln: University of Nebraska.

Rozin, P. \& Fallon, A. (1988). Body Image, Attitudes to Weight and Misperceptions of Figure Preferences of the Opposite Sex: A Comparison of Men and Women in Two Generations. Journal of Abnormal Psychology, vol.97, pp.342-45.

Seemanthini, T.S. (2015). Socio Cultural Attitude towards Appearance and Multidimensional Gender Consciousness in Men and Women - A Pilot Study. Journal of Psychological Research, vol.10:2, pp.239-248.

Sharan,P. \&Sundar, A.S. (2015).Eating Disorders in Women. Indian Journal of Psychiatry, vol.57:2, pp.286-295.

Snyder, M., Tanke, E. D. \& Berscheid, E. (1977). Social Perception and Interpersonal Behavior: On the Self-fulfilling Nature of Social Stereotypes. Journal of Personality and Social Psychology, vol.35, pp.656-666.

Statistics Canada (2002). Canadian Community Health Survey: A First Look. Retrieved February 8, 2005, from http://www.statcan.ca/Daily/English/020508/ d020508a.htm

Stanford, J. N., \& Mccabe, M. P. (2002). Body Image Ideal among Males and Females: Sociocultural Influences and Focus on Different Body Parts. Journal of Health Psychology, vol.7:6, pp.675-684. doi:10.1177/1359105302007006871

Stice, E. (2004). Review of the Evidence for a Sociocultural Model of Bulimia Nervosa and an Exploration of the Mechanism of Action. Clinical Psychology Review, vol.16, pp.633-631.

Stice, E., Schupak-Neuberg, E., Shaw, H. \& Stein, R. (1994). Relation of Media Exposure to Eating Disorder Symptomatology: An Examination of Mediating Mechanisms. Journal of Abnormal Psychology, vol.103:4, pp.836-840.

Sincero, S.M. (2012). Does Culture Affect our Personality? Retrieved Feb 17, 2018 from Explorable.com: https://explorable.com/culture-and-personality

Solomon, M. R., Zaichkowsky, J. L. \& Polegato, R. (2005). Consumer Behaviour: Buying, Having and Behaving (3rd ed.). Toronto: Prentice Hall. 
Sousa, VD. \& Rojjanasrirat, W. (2011). Translation, Adaptation and Validation of Instruments or Scales for Use in Cross-Cultural Health Care Research: A Clear and User-Friendly Guideline. Journal of Evaluation in Clinical Practice, vol.17, pp.268-274.

Tantleff-Dunn, S. \& Gokee, J. L. (2002). Interpersonal Influences on Body Image Development. In T. F. Cash \& T. Pruzinsky (Eds.), Body image: A Handbook of Theory, Research and Clinical Practice (pp. 143-154). New York: The Guilford Press.

Taqui, A. M., Shaikh, M., Gowani, S. A., Shahid, F., Khan, A., Tayyeb, S. M. \& Naqvi, H. A. (2008). Body Dysmorphic Disorder: Gender differences and prevalence in a Pakistani medical student population. BMC Psychiatry, vol.8:1.doi:10.1186/1471$244 \mathrm{x}-8-20$

Thompson, J. K., Heinberg, L., Anderson, D.A. \& Paxton, S.J. (2015).Development and Validation of the Sociocultural Attitudes towards Appearance Questionnaire4.Psychological Assessment, vol.27:1, pp.54-56.

Thompson, J. K. (1990). Body Image Disturbance: Assessment and Treatment. Elmsford. New York: Pergamon Press.

Thompson, J. K. \& Heinberg, L.J. (1999). The Media's Influence on Body Image Disturbance and Eating Disorders: We've Reviled Them, Now Can We Rehabilitate Them? Journal of Social Issues, vol.55:2, pp.339-353.

Thompson, J. K., Heinberg, L. J., Altabe, M. \& Tantleff-Dunn, S. (1999).Exacting Beauty. Washington, D. C.: American Psychological Association.

Thompson, J., van den Berg, P., Roehrig, M., Guarda, A. \& Heinberg, L. (2004). The Sociocultural Attitudes towards Appearance Questionnaire-3 (SATAQ-3): Development and validation. International Journal of Eating Disorders, vol.35, pp.293-304.

Thorndike, E. L. (1920). A Constant Error in Psychological Ratings. Journal of Applied Psychology, vol.4, pp.469-477.

Todorov, A., Mandisodza, A. N., Goren, A. \& Hall, C. C. (2005). Inferences of Competence from Faces Predict Election Outcomes. Science, vol.308, pp.1623-1626. 
Twamley, E. W. \& Davis, M. C. (1999). The Sociocultural Model of Eating Disturbance in Young Women: The Effects of Personal Attributes and Family Environment. Journal of Social and Clinical Psychology, vol.18:4, pp.467-489.

Vartanian, L. R., Giant, C. L. \& Passino, R. M. (2001). Ally McBeal vs. Arnold Schwarzenegger: Comparing Mass Media, Interpersonal Feedback and Gender as Predictors of Satisfaction with Body Thinness and Muscularity. Social Behavior \& Personality, vol.29:7, pp.711-723.

Vincent, M. A. \& McCabe, M. P. (2000).Gender Differences among Adolescents in Family and Peer Influences on Body Dissatisfaction, Weight Loss and Binge Eating Disorders. Journal of Youth and Adolescence, vol.29, pp.205-221.

Vocks, S., Stahn, C., Loenser, K. \& Legenbauer, T. (2009). Eating and Body Image Disturbances in Male-to-Female and Female-to-Male Trans Sexuals. Archives of Sexual Behavior, vol.38, pp.364-377.

Waaler-Loland, N.(1998). The Male Body-Ideals and Realities: A Study on Satisfaction and Concern with Physical Appearance among Physically Active and Inactive Norwegian men. Paper Presented at the International Sociological Association, Oslo, Norway.

Zebrowitz, L. A. (1996). Physical Appearance as a Basis of Stereotyping. In C. N. Macrae, C. Stangor, \& M. Hewstone (Eds.), Stereotypes and Stereotyping (pp. 79-121). New York: Guilford.

Zhang, L., Qian, H. \& Fu, H. (2018). To be Thin but not Healthy - The Body-Image Dilemma may Affect Health among Female University Students in China. Plos, vol.13:10, pp.1-14.

Asma Latif is a Ph.D Scholar in the Department of Psychology, University of Karachi, Karachi, Pakistan.

Dr. Bushra Khan is an Assistant Professor in the Department of Psychology, University of Karachi, Karachi, Pakistan. 